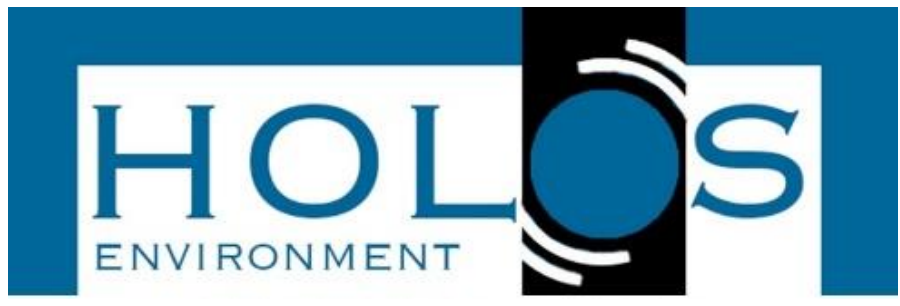

\title{
AVALIAÇÃO DE CHUMBO (PB), MERCÚRIO (HG) E CÁDMIO (CD) NO SEDIMENTO DE MARGEM DA REPRESA DO GUARAPIRANGA, UMA QUESTÃO DE SAÚDE PÚBLICA
}

\section{EVALUATION OF LEAD (PB), MERCURY (HG) AND CADMIUM (CD) IN THE MARGIN SEDIMENT OF THE GUARAPIRANGA DAM, A PUBLIC HEALTH ISSUE}

\author{
João Brogotá Perdigão Garcia ${ }^{1}$; Maria Regina Andrade de Azevedo ${ }^{1}$
}

Artigo recebido em: 05/05/2018 e aceito para publicação em: 20/05/2019.

DOI: http://dx.doi.org/10.14295/holos.v19i1.12291

Resumo: Um dos maiores reservatórios de água da zona sul de São Paulo, a represa do Guarapiranga, assistiu a ocupação irregular do manancial tomar proporções irreversíveis, comprometendo a qualidade da água com o lançamento de esgotos domésticos e industriais sem tratamento prévio, gerando aumento nos níveis de poluição ambiental. A alta concentração de metais pesados em especial nos sedimentos pode ser uma boa indicação de poluição muitas vezes atribuída a influências antropogênicas, ao invés de um enriquecimento natural dos sedimentos geológicos por intemperismo. Neste trabalho foram investigados seis pontos de coleta, escolhidos observando o acesso dos usuários da represa do Guarapiranga às chamadas "prainhas", onde buscam seu lazer e momento de descanso com suas famílias. No laboratório da Universidade Santo Amaro em São Paulo, as amostras foram secas à temperatura ambiente, destorroadas, peneiradas e após digestão ácida enviadas para a leitura em espectrômetro de absorção atômica. O resultado da investigação constatou a contaminação de $\mathrm{Cd}$ acima dos valores permitidos e a presença de $\mathrm{Pb}$ com valores acima e próximos do valor de referência de qualidade. Não foi observada a contaminação de $\mathrm{Hg}$ nas amostras coletadas. As concentrações dos metais $\mathrm{Cd}$ e $\mathrm{Pb}$ que excederam os limites nas amostras coletadas comprovam a necessidade de monitoramento contínuo deste sistema e evidenciam a ação antrópica direta nas condições da represa do Guarapiranga.

Palavras-chave: Sedimento. Contaminação. Metais pesados. Saúde Pública.

Abstract: One of the largest reservoirs of water in the southern zone of Sao Paulo, the Guarapiranga dam, witnessed the irregular occupation of the source, take irreversible proportions, compromising water quality with the launch of domestic and industrial sewage without previous treatment, generating an increase in the levels of environmental pollution. The high concentration of heavy metals in particular in the sediments can be a good indication of pollution often attributed to anthropogenic influences, rather than a natural enrichment of geological sediments by weathering. In this work, six collection points were investigated, observing the access of users to the Guarapiranga dam to the so-called "small beaches", where they seek their leisure and rest time with their families. In the laboratory of Santo Amaro University in São Paulo, the samples were dried at room temperature, dismantled, sieved and underwent to acid digestion before sent to be analyzed in atomic absorption spectrometer. The results of the investigation showed a contamination of $\mathrm{Cd}$ above the permitted values as well as the presence of $\mathrm{Pb}$ with values above and close to the quality benchmark. A contamination of $\mathrm{Hg}$ was not observed in the collected samples. The concentrations of the $\mathrm{Cd}$ and $\mathrm{Pb}$ metals that exceeded the

\footnotetext{
${ }^{1}$ Universidade Santo Amaro (UNISA), Santo Amaro, SP. E-mails: (joao.brogota@terra.com.br, $\underline{\text { mestradocienci- }}$ asdasaude@unisa.br)
} 
limits in the collected samples confirm the need for continuous monitoring of this system and evidence the direct anthropogenic action in the conditions of the Guarapiranga dam.

Palavras-chave: Sediment. Contamination. Heavy metals. Public Health.

\section{INTRODUÇÃO}

De acordo com a Agência Nacional de Águas ${ }^{1}$ a cidade de São Paulo é considerada o mais populoso aglomerado urbano do Brasil e uma das cinco maiores metrópoles do planeta, abrangendo trinta e nove municípios e concentrando quase vinte milhões de habitantes. Destes municípios, trinta e um estão inseridos no Sistema Integrado de Abastecimento de Água operado pela Companhia de Saneamento Básico de São Paulo (SABESP).

A SABESP possui uma capacidade nominal equivalente a $68,2 \mathrm{~m}^{3} / \mathrm{s}$ de água. Visto que a região metropolitana de São Paulo está situada nas cabeceiras da bacia do rio Tietê, local de baixa disponibilidade hídrica, esta importa $32,3 \mathrm{~m} / \mathrm{s}$ de água de bacias hidrográficas adjacentes. Dentro do contexto da Bacia Hidrográfica do Alto Tietê a montante da barragem de Pirapora com uma área de drenagem de 5.720 $\mathrm{km}^{2}$, está inserida a sub-região hidrográfica Cotia-Guarapiranga e seu principal reservatório, a represa do Guarapiranga, importante corpo d'água localizado na zona sul do município de São Paulo².

Até meados de 1927 as águas da represa do Guarapiranga eram utilizadas exclusivamente para a geração de energia elétrica, mas a constante falta de água na cidade de São Paulo culminou com a retirada de $4 \mathrm{~m}^{3}$ de suas águas e inauguração da primeira adutora em 1929. Ao final dos anos quarenta a zona sul da cidade de São Paulo teve sua ocupação pela classe trabalhadora, mas foi durante a década de 1960 que após a realização de inúmeras obras de acesso à região da represa do Guarapiranga e seu entorno ocorreu a instalação do parque industrial de Santo Amaro, provocando uma demanda por habitação na região iniciando a ocupação irregular nas margens da represa, áreas definidas posteriormente como de proteção ambiental ${ }^{2}$.

A ocupação irregular do manancial tomou proporções irreversíveis, comprometendo a qualidade da água da represa com o lançamento de esgotos domésticos e das indústrias metalúrgicas sem nenhum tratamento primário gerando aumento 
nos níveis de poluição ambiental, causando problemas para o ecossistema, principalmente devido à alteração química².

Ainda que o solo tenha função de depurar grande parte das impurezas depositadas, sua capacidade é limitada ocorrendo alteração da composição e qualidade devido ao efeito cumulativo de agentes agressores atmosféricos, da aplicação de fertilizantes, da disposição de resíduos sólidos industriais, urbanos, materiais tóxicos e radioativos ${ }^{3}$.

Para Marques et $\mathrm{al}^{4}$ os poluentes inorgânicos mais tóxicos que ocorrem em solos são os metais pesados ou metais traço, um grupo de elementos com densidade atômica maior que $5 \mathrm{~g} / \mathrm{cm}^{3}$ ou número atômico maior que 20. A alta concentração de metais pesados em especial nos sedimentos pode ser uma boa indicação de poluição muitas vezes atribuída a influências antropogênicas, ao invés de um enriquecimento natural dos sedimentos geológicos por intemperismo ${ }^{5}$. As fontes corriqueiras de metais pesados no ambiente têm origem nos fertilizantes, defensivos agrícolas, das emissões veiculares, da combustão de carvão e óleo, mineração, fundição, incineração e refinação de resíduos urbanos e industriais, que em torno de $95 \%$ de $\mathrm{Hg}$, $90 \%$ de $\mathrm{Cd}$, 33\% de $\mathrm{Pb}$ e $27 \%$ de $\mathrm{Zn}$ (zinco) são perdidos na forma de particulados e gases quando queimados ${ }^{6}$.

Os sedimentos para Ferreira, Horta e Cunha ${ }^{7}$ integram os contaminantes ao longo do tempo e estão em constante fluxo sobrejacente com a coluna d'água. A análise dos metais pesados nos sedimentos permite a detecção de poluentes que podem até estarem ausentes ou em baixas concentrações na coluna d'água fornecendo um registro da história temporal da poluição em uma determinada região ou ecossistema.

Com a crise hídrica de 2014, o volume de água da represa do Guarapiranga, responsável pelo abastecimento de nove milhões de habitantes da região metropolitana de São Paulo, chegou a $20 \%$ de sua capacidade, conforme noticiado pela Empresa Brasileira de Comunicação - $\mathrm{EBC}^{8}$. Tal fato aliado ao uso frequente das áreas às margens da represa com a finalidade de lazer, cultivo de vegetais, criadouros de animais de pequeno, médio e grande porte, pesca para consumo e outras atividades com fins exploratórios, torna a avaliação da concentração de metais pesados como chumbo, mercúrio e cádmio, tóxicos ao organismo humano uma preocupação constante. 


\section{METODOLOGIA}

\subsection{Descrição da Área de estudo}

O estudo foi realizado na represa do Guarapiranga que está inserida na porção sudoeste da Região Metropolitana de São Paulo, formado pelo represamento do rio Guarapiranga, sendo os rios Parelheiros, Embu Mirim, Embu Guaçu e seu afluente, o Ribeirão Santa Rita, seus principais tributários.

Apresenta um perímetro de $85 \mathrm{~km}$, área de espelho d'água de $26,6 \mathrm{~km}^{2}$, volume de $180 \mathrm{hm}^{3}$ e profundidades média e máxima de $5,7 \mathrm{~m}$ e $13 \mathrm{~m}$, respectivamente. Localizada a $23^{\circ} 43^{\prime \prime}$ latitude sul, $46^{\circ} 32^{\prime \prime}$ Iongitude oeste de Greenwich e em altitude de $740 \mathrm{~m}$.

\subsection{Coleta das amostras de sedimento}

Seis pontos de coleta foram escolhidos observando o acesso e quantidade de frequentadores da represa do Guarapiranga às chamadas "prainhas", onde buscam seu lazer e momento de descanso com suas famílias, permanecendo vulneráveis aos efeitos do contato dérmico ou inalação do sedimento. (Figura 1).

Figura 1 - Pontos de coleta de amostras de sedimentos na represa do Guarapiranga 2016

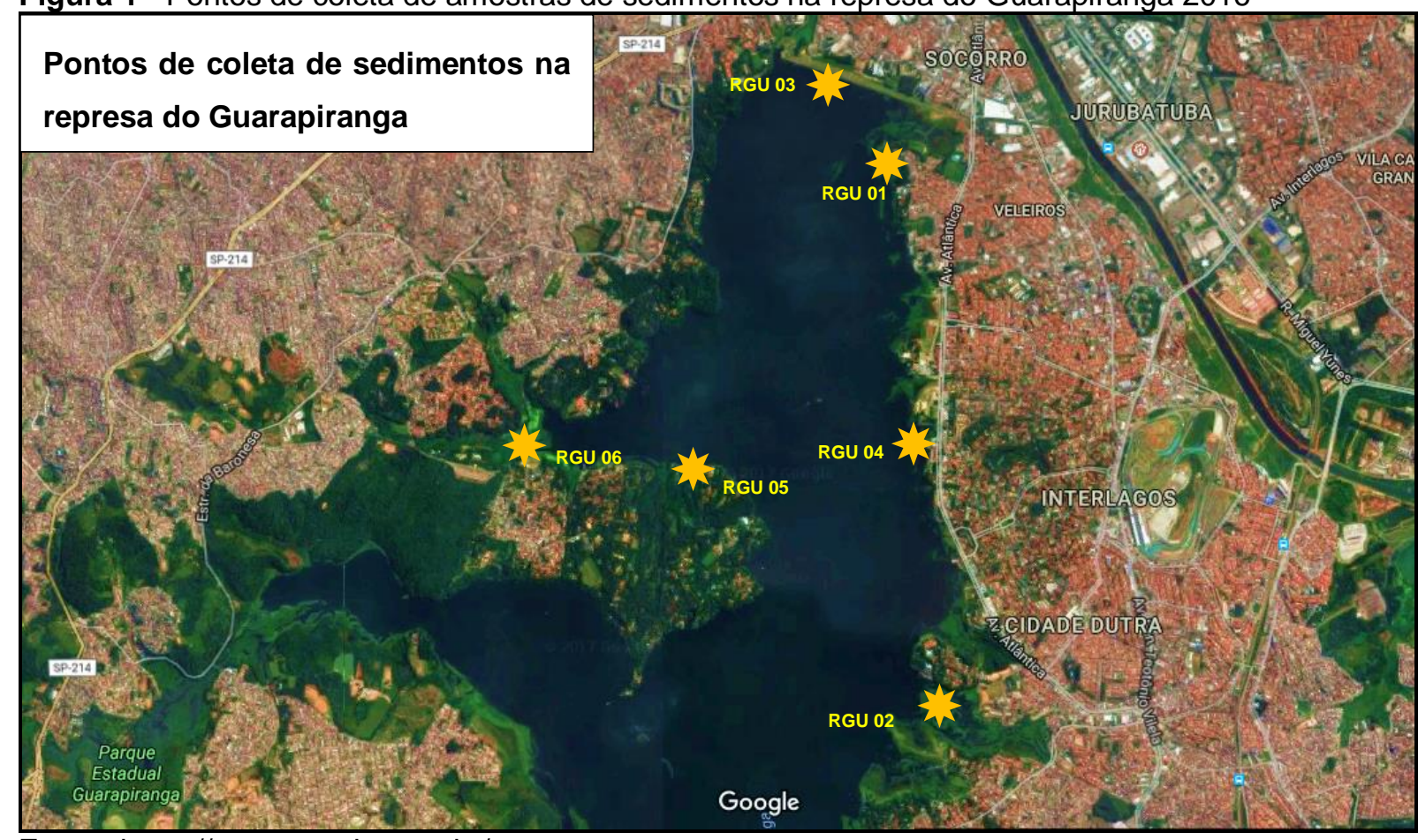

Fonte: https://www.google.com.br/maps 
De cada ponto de coleta, foram coletadas em triplicatas $0,500 \mathrm{Kg}$ de cada amostra, diretamente dos sedimentos de margem, até a camada de $20 \mathrm{~cm}$ de profundidade no substrato, utilizando a pá estreita e transportadas em bolsas plásticas herméticas. As amostras RGU 01 e RGU 02 foram coletadas durante o mês de junho de 2016 e as amostras RGU 03, RGU 04, RGU 05 e RGU 06 durante o mês de dezembro de 2016.

RGU 01: ATI Parque da Barragem, Orla Guarapiranga situado a Avenida João de Barros com Avenida Atlântica, bairro do Socorro no município de São Paulo, portão de acesso pela Avenida Dr. Caetano Petralia Sobrinho junto ao limite divisório do parque com o São Paulo Yatch Club, nas coordenadas geográficas $23^{\circ} 40^{\prime} 36.9^{\prime \prime S}$ e $46^{\circ} 43^{\prime} 03.5^{\prime \prime} \mathrm{W}$.

RGU 02: Próximo ao Clube de Campo do Castelo situado a Avenida Alcindo Ferreira no bairro Interlagos no município de São Paulo as margens da represa do Guarapiranga, ao lado dos campos de futebol, nas coordenadas geográficas $23^{\circ} 43^{\prime} 01.0^{\prime \prime} S$ e $46^{\circ} 42^{\prime} 43.0^{\prime \prime} \mathrm{W}$.

RGU 03: Barragem do Rio Guarapiranga, ao lado do ponto da captação de água da SABESP destinada à unidade de tratamento do Alto da Boa Vista, nas coordenadas geográficas $23^{\circ} 40^{\prime} 18.7^{\prime \prime S}$ e $46^{\circ} 43^{\prime} 31.6^{\prime \prime} \mathrm{W}$.

RGU 04: Defronte ao heliponto da polícia militar do estado de São Paulo no posto de bombeiros de salvamento aquático, nas coordenadas geográficas $23^{\circ} 41^{\prime} 56.4^{\prime \prime S}$ e $46^{\circ} 42^{\prime} 58.1^{\prime \prime W}$.

RGU 05: Rua Açucena do Campo no bairro Praia Azul no final da Estrada do Riviera acesso a prainha, nas coordenadas geográficas $23^{\circ} 42^{\prime} 01.4^{\prime \prime S}$ e $46^{\circ} 44^{\prime} 09.1^{\prime \prime} \mathrm{W}$.

RGU 06: Ao lado do playground infantil dentro do Parque Ecológico do Guarapiranga paralelo a Rua Água da Figueira, nas coordenadas geográficas $23^{\circ} 42^{\prime} 00.8^{\prime \prime S}$ e $46^{\circ} 44^{\prime} 52.5 " \mathrm{~W}$.

\subsection{Preparo das amostras de sedimento}

As amostras foram secas à temperatura ambiente durante três dias, posteriormente destorroadas com auxílio do martelo de borracha, peneiradas através de malha de aço de $0,5 \mathrm{~mm}$. Em seguida foram submetidas à digestão ácida em banho- 
maria com ácido nítrico e ácido clorídrico ambos concentrados, conforme descrito: procedeu-se a pesagem de $0,5 \mathrm{~g}$ de cada amostra em balança analítica, acondicionadas em cadinho de porcelana com a adição de $9 \mathrm{~mL}$ de ácido nítrico e $3 \mathrm{~mL}$ de ácido clorídrico concentrados, levando a banho-maria por 90 minutos.

Após 30 minutos de repouso obteve-se seu resfriamento, acondicionado em balão volumétrico de $50 \mathrm{ml}$, completando com água deionizada o volume total. Após filtragem em papel Micropore ${ }^{\circledR} 0,45 \mu \mathrm{m}$ millipore, as soluções foram enviadas para a leitura em espectrômetro de emissão atômica, conforme descrito no trabalho de Moraes e Horn?.

\subsection{Determinação da concentração de metais pesados}

Os metais pesados $(\mathrm{Pb}, \mathrm{Hg}$ e $\mathrm{Cd})$ das amostras de sedimentos foram determinados por espectrômetro de emissão atômica de plasma (ICP 03), marca Varian, modelo Vista MPX, através do método ASTM D 1976: 2012 - Standart Test Method for Elements in Water by Inductively-Coupled Argon Plasma Atomic Emission Spetroscopy. (Determinação de metais em água e efluentes por espectrometria de plasma - procedimento CQuiM-LAQ-PE-QI-018 Rev. 13 de 28.01.2016), nos laboratórios do Instituto de Pesquisas Tecnológicas - IPT e Instituto de Oceanografia - IO da USP. A figura 2 mostra cada metal medido e os valores orientadores para solo segundo a CETESB $2014^{10}$ (Figura 2).

Figura 2 - Valores orientadores para Metais Pesados (CETESB 2014) ${ }^{10}$ 


\begin{tabular}{|c|c|c|c|c|c|c|c|}
\hline \multirow{3}{*}{ Substância } & \multirow{3}{*}{ CAS No } & \multicolumn{5}{|c|}{ Solo (mg kg ${ }^{-1}$ peso seco) } & \multirow{3}{*}{$\begin{array}{c}\text { Água Subterrânea } \\
\left(\mu \mathrm{g}^{-1}\right) \\
\text { VI }\end{array}$} \\
\hline & & \multirow{2}{*}{$\begin{array}{c}\text { Valor de } \\
\text { Referência } \\
\text { Qualidade }\end{array}$} & \multirow{2}{*}{$\begin{array}{c}\begin{array}{c}\text { Valor de } \\
\text { Prevenção }\end{array} \\
\text { (VP) }\end{array}$} & \multicolumn{2}{|c|}{ Valor de Intervenção } & (VI) & \\
\hline & & & & Agrícola & Residencial & Industrial & \\
\hline \multicolumn{8}{|l|}{ INORGÂNICOS } \\
\hline Antimônio $^{(1)}$ & $7440-36-0$ & $<0,5$ & 2 & 5 & 10 & 25 & 5 \\
\hline Arsênio $^{(1)}$ & $7440-38-2$ & 3,5 & 15 & 35 & 55 & 150 & 10 \\
\hline Bário & $7440-39-3$ & 75 & 120 & 500 & 1300 & 7300 & 700 \\
\hline Boro & $7440-42-8$ & - & - & - & - & - & 2400 \\
\hline Cádmio & $7440-43-9$ & $<0,5$ & 1,3 & 3,6 & 14 & 160 & 5 \\
\hline Chumbo & $7439-92-1$ & 17 & 72 & 150 & 240 & 4400 & 10 \\
\hline Cobalto $^{(1)}$ & $7440-48-4$ & 13 & 25 & 35 & 65 & 90 & 70 \\
\hline Cobre $^{(2)}$ & $7440-50-8$ & 35 & 60 & 760 & 2100 & $10000^{(2)}$ & 2000 \\
\hline Crômio total ${ }^{[2]}$ & $7440-47-3$ & 40 & 75 & 150 & 300 & 400 & 50 \\
\hline Crômio hexavalente & $18540-29-9$ & - & - & 0,4 & 3,2 & 10 & - \\
\hline Mercúrio & $7439-97-6$ & 0,05 & 0,5 & 1,2 & 0,9 & 7 & 1 \\
\hline Molibdênio & $7439-98-7$ & $<4$ & 5 & 11 & 29 & 180 & 30 \\
\hline Níquel $^{(2)}$ & $7440-02-0$ & 13 & 30 & 190 & 480 & 3800 & 70 \\
\hline Nitrato (como N) & $14797-55-8$ & - & - & - & - & - & 10000 \\
\hline Prata ${ }^{[1]}$ & $7440-22-4$ & 0,25 & 2 & 25 & 50 & 100 & 50 \\
\hline Selênio & $7782-49-2$ & 0,25 & 1,2 & 24 & 81 & 640 & 10 \\
\hline Zinco & $7440-66-6$ & 60 & 86 & 1900 & 7000 & $10000^{(0)}$ & 1800 \\
\hline
\end{tabular}

\subsection{Valores orientadores de qualidade de sedimento utilizados no estudo}

Neste trabalho para obtenção comparativa dos resultados foram utilizados ainda como referencial os valores orientadores de qualidade de sedimento estabelecidos pelo Canadian Council of Ministers of the Environment (CCME, 1995) ${ }^{11}$, que de acordo com o Ministério do Meio Ambiente ${ }^{12}$, dividem-se em dois níveis: o mais baixo, denominado TEL (threshold effect level) e o mais alto, denominado PEL (probable effect level), delimitam intervalos de probabilidade de ocorrência de efeitos biológicos adversos e os valores orientadores da Resolução no 344 de 25 de março de 2004 do CONAMA $^{13}$ que estabelece as diretrizes gerais e os procedimentos mínimos para a avaliação do material a ser dragado em águas jurisdicionais brasileiras (Tabela1).

Tabela 1 - Valores orientadores de qualidade no sedimento, adaptado CETESB 2014 ${ }^{10}$, CCME $1995^{11}$ e CONAMA $2004^{13}$

Valores orientadores de qualidade de sedimento $\mathrm{mg} / \mathrm{Kg}$

\begin{tabular}{l|cc|cc|cc}
\hline & \multicolumn{2}{|c|}{ CETESB 2014 } & \multicolumn{2}{c|}{ CCME 1995 } & \multicolumn{2}{c}{ CONAMA 2004 } \\
\hline \multicolumn{1}{c|}{ Metal pesado } & VRQ & VP & TEL & PEL & Nível 1 & Nível 2 \\
\hline Chumbo (Pb) & 17 & 72 & 35 & 91,3 & 35 & 91,3 \\
Mercúrio (Hg) & 0,05 & 0,5 & 0,17 & 0,486 & 0,17 & 0,486 \\
Cádmio (Cd) & $<0,5$ & 1,3 & 0,6 & 3,5 & 0,6 & 3,5 \\
\hline
\end{tabular}




\section{RESULTADOS}

Foram investigadas as concentrações de metais pesados: $\mathrm{Pb}, \mathrm{Hg}$ e $\mathrm{Cd}$ no sedimento às margens da represa do Guarapiranga em seis pontos considerados críticos pela vulnerabilidade aos usuários e seus resultados apresentados na Tabela 2. Todas as amostras investigadas, sem exceção, apresentaram valores não significativos para presença de $\mathrm{Hg}$, variando de $0,00000541 \mathrm{mg} / \mathrm{Kg}$ à $0,00000000 \mathrm{mg} / \mathrm{Kg}$ (Figura 3).

Quanto a presença de Cd, a amostra RGU 01 mostrou resultado de $1,4 \mathrm{mg} / \mathrm{Kg}$, número acima dos limites dos valores orientadores da $\mathrm{CETESB}^{10}$, seja para o valor de referência de qualidade (VRQ), maior que $0,5 \mathrm{mg} / \mathrm{kg}$ ou valor de prevenção (VP) maior que $1,3 \mathrm{mg} / \mathrm{Kg}$ para solo. Excede os valores de sedimento em água fresca de 0,6 mg/Kg TEL do CCME ${ }^{11}$ e nível 1 da Resolução no 344 de 25 de março de 2004 do CONAMA $^{13}$ (Figura 4).

Nesta mesma amostra, RGU 01, a concentração de $\mathrm{Pb}$ mostrou um resultado igual a $19,5 \mathrm{mg} / \mathrm{kg}$, considerado acima do valor de referência de qualidade da CETESB $^{10}$ e abaixo dos valores TEL do CCME $^{11}$ e nível 1 do CONAMA $^{13}$ (Figura 5).

Tabela 2- Concentração de metais pesados no sedimento das amostras coletadas e valores orientadores de qualidade de sedimento $\mathrm{em} \mathrm{mg} / \mathrm{Kg}$.

\begin{tabular}{|c|c|c|c|c|c|c|c|c|c|c|c|c|}
\hline \multirow[b]{3}{*}{$\begin{array}{l}\text { Metal } \\
\text { pesado }\end{array}$} & \multicolumn{6}{|c|}{ Média resultante das triplicatas coletadas $(\mathrm{mg} / \mathrm{Kg})$} & \multicolumn{6}{|c|}{$\begin{array}{c}\text { Valores orientadores de qualidade de } \\
\text { sedimento }(\mathrm{mg} / \mathrm{Kg})\end{array}$} \\
\hline & \multirow[b]{2}{*}{ RGU 01} & \multirow[b]{2}{*}{ RGU 02} & \multirow[b]{2}{*}{ RGU 03} & \multirow[b]{2}{*}{ RGU 04} & \multirow[b]{2}{*}{ RGU 05} & \multirow[b]{2}{*}{ RGU 06} & \multicolumn{2}{|c|}{$\begin{array}{r}\text { CETESB } \\
2014 \\
\end{array}$} & \multicolumn{2}{|c|}{$\begin{array}{r}\text { CCME } \\
1995 \\
\end{array}$} & \multicolumn{2}{|c|}{ CONAMA 2004} \\
\hline & & & & & & & VRQ & VP & TEL & PEL & Nível 1 & $\begin{array}{r}\text { Nível } \\
2 \\
\end{array}$ \\
\hline $\begin{array}{c}\text { Chumbo } \\
\text { (Pb) } \\
\text { Mercúrio }\end{array}$ & 19,5 & 16 & 13 & 13 & 9,98 & 16 & 17 & 72 & 35 & 91,3 & 35 & 91,3 \\
\hline $\begin{array}{l}(\mathrm{Hg}) \\
\text { Cádmio }\end{array}$ & 0,0000871 & 0,00000541 & 0 & 0 & 0 & 0 & 0,05 & 0,5 & 0,17 & 0,486 & 0,17 & 0,486 \\
\hline$(\mathbf{C d})$ & 1,4 & 0,33 & 0,99 & 0,99 & 0,99 & 0,99 & $<0,5$ & 1,3 & 0,6 & 3,5 & 0,6 & 3,5 \\
\hline
\end{tabular}

Figura 3 - Concentração de Hg nas amostras coletadas 


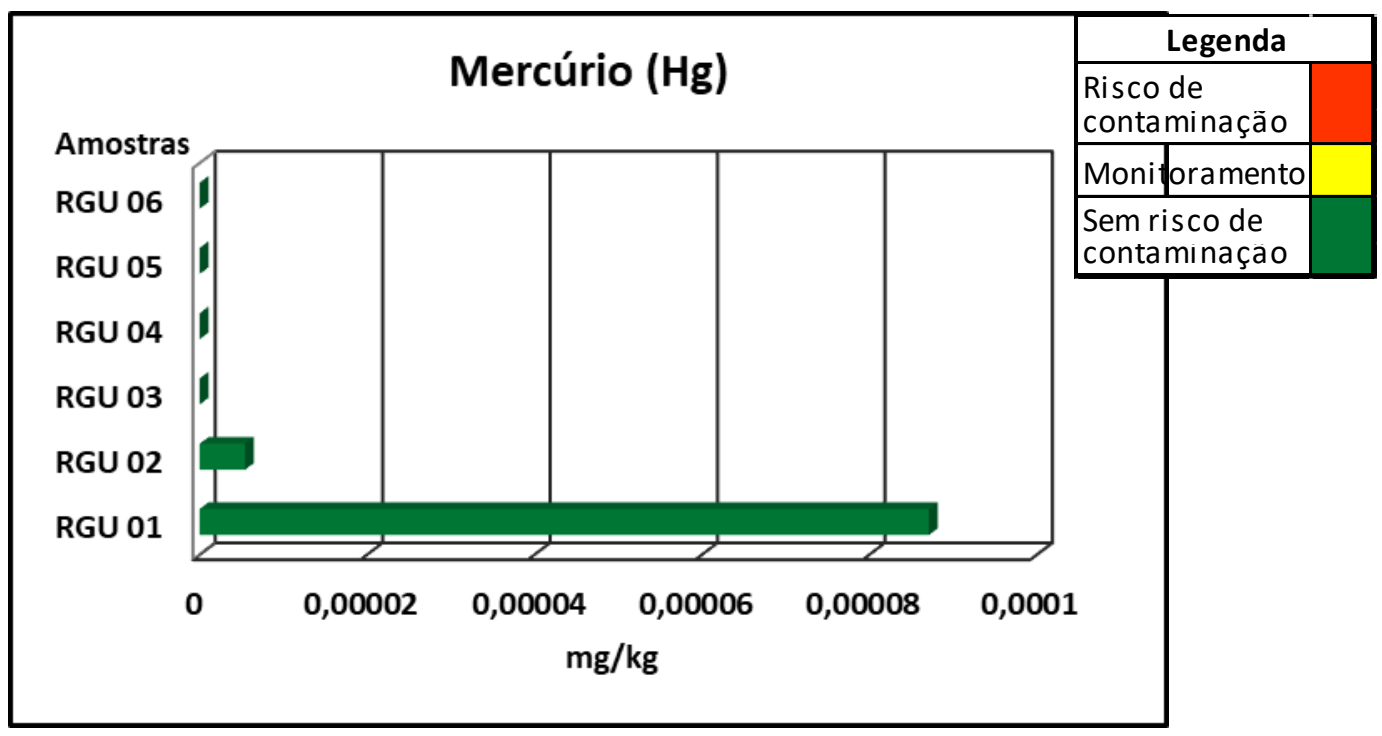

\begin{tabular}{|c|c|c|c|c|c|c|c|c|c|c|c|c|}
\hline \multirow{3}{*}{\begin{tabular}{|l} 
Substância \\
inorgânica \\
(Metal pesado) \\
\end{tabular}} & \multirow{2}{*}{\multicolumn{6}{|c|}{ Média resultante das amostras coletadas $-\mathrm{mg} / \mathrm{Kg}$}} & \multicolumn{6}{|c|}{ Valores orientadores de qualidade de sedimento $-\mathrm{mg} / \mathrm{Kg}$} \\
\hline & & & & & & & \multicolumn{2}{|c|}{ CETESB 2014} & \multicolumn{2}{|c|}{ CCME 1995} & \multicolumn{2}{|c|}{ CONAMA 2004} \\
\hline & RGU 01 & RGU 02 & RGU 03 & RGU 04 & RGU 05 & RGU 06 & VRQ & VP & TEL & PEL & Nível 1 & Nível 2 \\
\hline Mercúrio (Hg) & 0,0000871 & 0,00000541 & 0 & 0 & 0 & 0 & 0,05 & 0,5 & 0,17 & 0,486 & 0,17 & 0,486 \\
\hline
\end{tabular}

Figura 4 - Concentração de Cd nas amostras coletadas

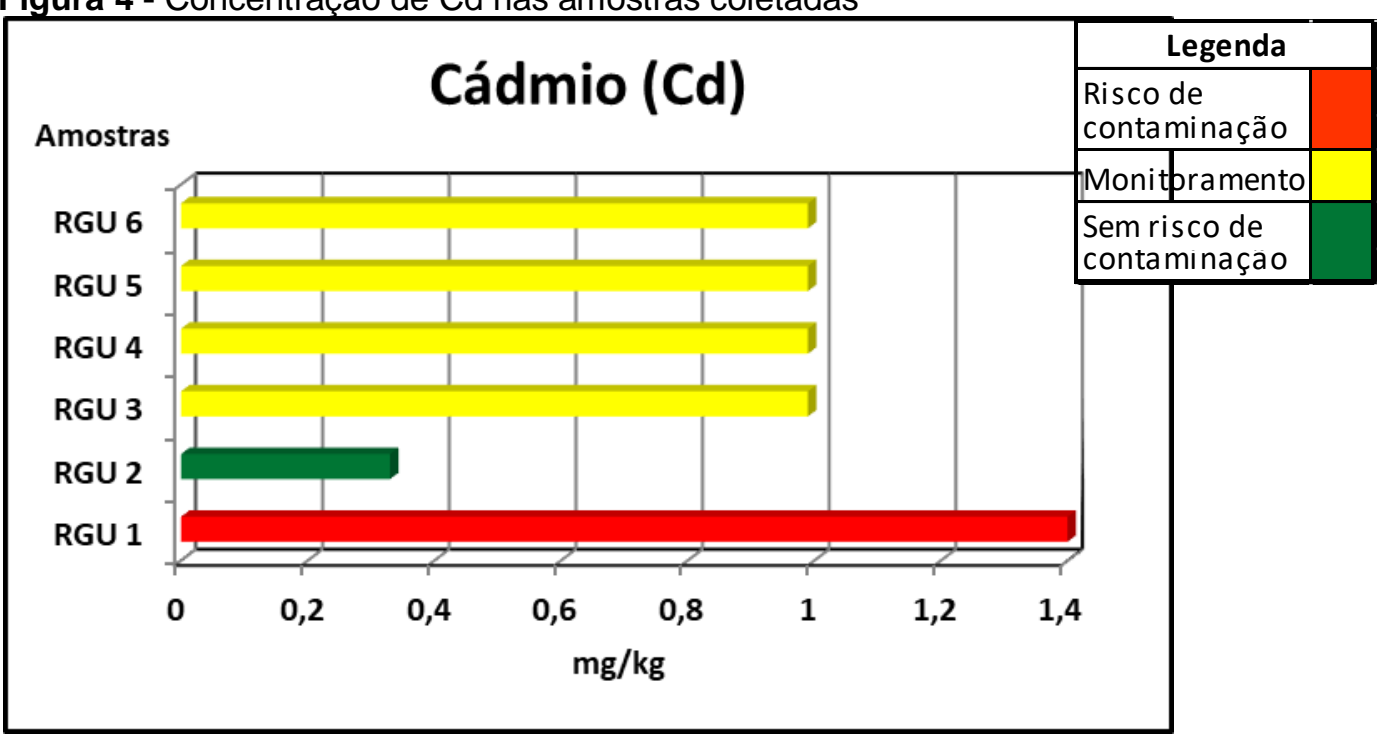




\begin{tabular}{|c|c|c|c|c|c|c|c|c|c|c|c|c|}
\hline \multirow{3}{*}{$\begin{array}{l}\text { Substância } \\
\text { inorgânica } \\
\text { (Metal pesado) }\end{array}$} & \multirow{2}{*}{\multicolumn{6}{|c|}{ Média resultante das amostras coletadas $-\mathrm{mg} / \mathrm{Kg}$}} & \multicolumn{6}{|c|}{ Valores orientadores de qualidade de sedimento $-\mathrm{mg} / \mathrm{Kg}$} \\
\hline & & & & & & & \multicolumn{2}{|c|}{ CETESB 2014} & \multicolumn{2}{|c|}{ CCME 1995} & \multicolumn{2}{|c|}{ CONAMA 2004} \\
\hline & RGU 01 & RGU 02 & RGU 03 & RGU 04 & RGU 05 & RGU 06 & VRQ & VP & TEL & PEL & Nível 1 & Nível 2 \\
\hline Cádmio (Cd) & 1,4 & 0,33 & 0,99 & 0,99 & 0,99 & 0,99 & $<0,5$ & 1,3 & 0,6 & 3,5 & 0,6 & 3,5 \\
\hline
\end{tabular}

Figura 5 - Concentração de Pb nas amostras coletadas

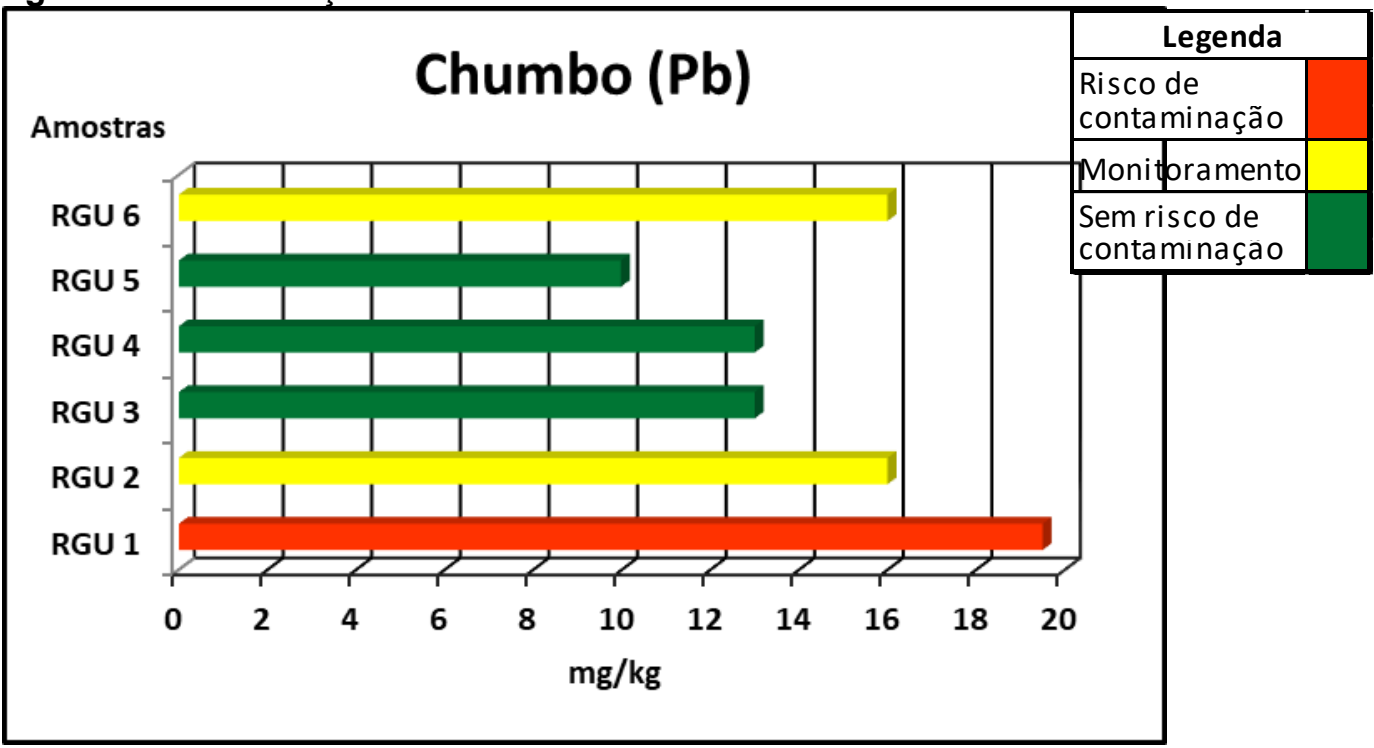

\begin{tabular}{|c|c|c|c|c|c|c|c|c|c|c|c|c|}
\hline \multirow{3}{*}{\begin{tabular}{|l} 
Substância \\
inorgânica \\
(Metal pesado) \\
\end{tabular}} & \multirow{2}{*}{\multicolumn{6}{|c|}{ Média resultante das amostras coletadas - $\mathrm{mg} / \mathrm{Kg}$}} & \multicolumn{6}{|c|}{ Valores orientadores de qualidade de sedimento $-\mathrm{mg} / \mathrm{Kg}$} \\
\hline & & & & & & & \multicolumn{2}{|c|}{ CETESB 2014} & \multicolumn{2}{|c|}{ CCME 1995} & \multicolumn{2}{|c|}{ CONAMA 2004} \\
\hline & RGU 01 & RGU 02 & RGU 03 & RGU 04 & RGU 05 & RGU 06 & VRQ & VP & TEL & PEL & Nível 1 & Nível 2 \\
\hline Chumbo (Pb) & 19,5 & 16 & 13 & 13 & 9,98 & 16 & 17 & 72 & 35 & 91,3 & 35 & 91,3 \\
\hline
\end{tabular}

\section{DISCUSSÃO}

Os sedimentos não têm sido considerados apenas como reservatórios de agentes contaminantes para o meio ambiente, mas como compartimento aquático ativo capaz de interferir nos ecossistemas adjacentes. Nesse contexto os metais pesados devem ser vistos com atenção, pois não são degradados naturalmente e tão pouco permanecem fixados nos sedimentos, retornando ao corpo d'água através de alterações de suas propriedades físico-químicas ${ }^{9}$.

Neste estudo foi observado um aumento da concentração de $\mathrm{Cd}$ na amostra RGU 01 de acordo com os parâmetros de qualidade do sedimento. A intoxicação pelo cádmio tem como principal característica, a insuficiência renal e/ou pulmonar, podendo causar sérios danos ao indivíduo. Diante da possibilidade de contaminação através da inalação de partículas em suspensão pelas vias respiratórias, ingestão pelo trato gastrointestinal ${ }^{14}$ ou absorção dérmica ${ }^{15}$, medidas preventivas para minimizar estes efeitos devem ser estabelecidas no local. As amostras RGU 03, RGU 
04, RGU 05 e RGU 06 apresentaram valores de Cd iguais a $0,99 \mathrm{mg} / \mathrm{Kg}$ considerados acima do valor de referência de qualidade da CETESB, ${ }^{10} \mathrm{TEL}$ do $\mathrm{CCME}^{11}$ e nível 1 do $\operatorname{CONAMA}^{13}$ porém abaixo do valor de prevenção da CETESB, ${ }^{10}$ PEL do $\mathrm{CCME}^{11}$ e nível 2 do $\mathrm{CONAMA}^{13}$ preconizando um estado de atenção nestes locais.

A contaminação de chumbo nos solos é um processo cumulativo praticamente irreversível, provocando aumento considerável dos teores desse metal na superfície do solo, indicando uma disponibilidade de absorção pelas raízes das plantas. $O$ $\mathrm{Pb}$ interfere diretamente em órgãos como os rins, medula óssea e o sistema nervoso provocando a desmielinização e a degeneração dos axônios, prejudicando funções psicomotoras e neuromusculares, interfere na biossíntese da heme contribuindo para o surgimento de anemia sideroblástica, altera os processos genéticos ou cromossômicos, inibindo o reparo de DNA e age como promotor na formação de neoplasi$\mathrm{as}^{16}$.

A presença de $\mathrm{Pb}$ na amostra RGU 01 com resultante igual a $19,5 \mathrm{mg} / \mathrm{Kg}$, pede o monitoramento imediato embasado nos parâmetros da CETESB ${ }^{10}$, preconizando medidas corretivas para fins de saúde pública. As amostras RGU 02 e RGU 06 com valores de $16 \mathrm{mg} / \mathrm{kg}$, sugerem um estado de atenção devido ao valor próximo ao de referência de qualidade da $\mathrm{CETESB}^{10}$. Cabe ressaltar que os locais onde foram coletadas as amostras RGU 01, RGU 02 e RGU 06 constituem áreas públicas com maior frequência de usuários, devendo, portanto, ser alvo de monitoramento constante deste metal.

Em todas as amostras coletadas em que se observa a presença de $\mathrm{Cd}$ ou de $\mathrm{Pb}$ acima ou próximo dos valores de referência, indicam a necessidade de medidas remediadoras o mais breve possível, pois quanto maior o tempo de espera maior é o acúmulo deste metal no sedimento ali existente e maior é o risco de exposição e contaminação. Torna-se preocupante a exposição do ser humano aos metais pesados quando em contato com o meio ambiente, especialmente pelo ar, poeiras, solo, água, sedimentos, biota e alimentos por vias respiratórias, cutâneas, digestivas e placentárias ${ }^{17}$. O usuário fica exposto as áreas descritas neste trabalho, pois faltaIhe o conhecimento e a orientação dos órgãos públicos competentes de provável área contaminada com a presença deste metais, inalando as poeiras dos sedimentos secos ou absorvendo dermicamente os compostos tóxicos existentes nos sedimentos semissólidos às margens ou de fundo da represa do Guarapiranga durante a sua estadia de lazer, sendo portanto indispensável o monitoramento constante dos 
metais pesados no sedimento da represa e a busca de alternativas para minimizar os impactos ambientais e à saúde coletiva.

\section{CONCLUSÕES}

Observou-se a contaminação de Cd acima dos valores permitidos na amostra RGU 01 do sedimento coletado no ATI Parque da Barragem, Orla Guarapiranga situado a Avenida João de Barros com Avenida Atlântica, bairro do Socorro no município de São Paulo, portão de acesso pela Avenida Dr. Caetano Petralia Sobrinho junto ao limite divisório do parque com o São Paulo Yatch Club, requerendo procedimentos de monitoramento e correção nesta região. A presença de $\mathrm{Pb}$ na amostra RGU 01, mostrou números acima do valor de referência de qualidade preconizando risco de contaminação devendo, portanto, ser monitorada.

Não foi constatada a contaminação por $\mathrm{Hg}$ no sedimento das amostras coletadas.

As concentrações dos metais $\mathrm{Cd}$ e $\mathrm{Pb}$ que excederam os limites nas amostras coletadas comprovam a necessidade de monitoramento contínuo deste sistema e evidenciam a ação antrópica direta nas condições da represa do Guarapiranga.

\section{REFERÊNCIAS}

1. BRASIL. Agência Nacional de Águas (ANA). Atlas Brasil: abastecimento urbano de água: panorama nacional. Brasília: ANA; 2010. 2 v. Disponível em:

http://atlas.ana.gov.br/Atlas/downloads/atlas/Resumo\%20Executivo/Atlas\%20Brasil\%20\%20Volume\%201\%20-\%20Panorama\%20Nacional.pdf. Acesso em: 12 abr. 2016.

2. COMPANHIA DE SANEAMENTO BÁSICO DO ESTADO DE SÃO PAULO (SABESP). Espaço das Águas. Fundação Patrimônio Histórico da Energia e Saneamento. Dossiê Sistema Guarapiranga. São Paulo; 2008. Disponível em:

http://memoriasabesp.sabesp.com.br/acervos/dossies/pdf/9_sistema_guarapiranga. Acesso em: 12 abr. 2016.

3. CAROLINO CR. Avaliação da lei específica da área de proteção e recuperação de mananciais da bacia hidrográfica do Guarapiranga: contribuições para o aprimoramento da articulação institucional à proteção de mananciais [dissertação]. São Paulo: Universidade de São Paulo; 2015. Disponível em:http://www.teses.usp.br/teses/disponiveis/6/6134/tde26112015-105013/es.php. Acesso em: 23 abr. 2016.

4. MARQUES JJGSM, CURI N, SHULZE DG. Trace elements in cerrado soils. In: ALVAREZ VH; SHAEFER CGR; BARROS NF; MELLO JVW; COSTA LM. Tópicos em Ciência do solo. Viçosa. Sociedade Brasileira de Ciência do Solo. 2002. cap 3. p.103-142 
5. FERREIRA JG. Avaliação de parâmetros ambientais em aterros sanitários - estudo de caso. Taubaté 2006. Disponível em: http://livros01.livrosgratis.com.br/cp005033.pdf. Acesso em: 15 maio 2016.

6. DUARTE RPS, PASQUAL A. Avaliação do cádmio (Cd), chumbo (Pb), níquel (Ni) e zinco (Zn) em solos, plantas e cabelos humanos. Energ Agric. v.15, n. 1, p. 46-58, 2000. Disponível em:

https://www.researchgate.net/publication/242196709_avaliacao_do_cadmio_cd_chumbo_pb niquel_ni_e_zinco_zn_em_solos_plantas_e_cabelos_humanos 1 : $\bar{A} c e s s o$ em: 08 maio 2016.

7. FERREIRA AP, HORTA MAP e CUNHA CLN. Avaliação das concentrações de metais pesados no sedimento, na água e nos órgãos de Nycticorax nycticorax (Garça-da-noite) na Baía de Sepetiba, RJ, Brasil. 2010. Revista da Gestão Costeira Integrada, v. 10, n. 2, p. 229-241, 2010. Disponível em: http://www.aprh.pt/rgci/pdf/RGCl10f2.pdf. Acesso em: 15 maio 2016.

8. EMPRESA BRASILEIRA DE COMUNICAÇÃO - EBC. Volume de Guarapiranga chega a 20\%. 03 de julho de 2014. Disponível em:

http://www.ebc.com.br/noticias/brasil/2014/07/volume-de-guarapiranga-chega-a-20. Acesso em: 15 maio 2016.

9. MORAES PPF e HORN AH. Teores dos metais pesados $\mathrm{Cr}$, $\mathrm{Cd}$ e $\mathrm{Zn}$ em perfis de solos de veredas da bacia do rio do Formoso, município de Buritizeiro, Minas Gerais.

GEONOMOS, v. 18, n. 2, p. 78 - 85, 2010. Disponível em:

http://www.igc.ufmg.br/geonomos/PDFs/2.5_Moraes\&Horn_78_85.pdf. Acesso em: 31 maio 2016.

10. COMPANHIA AMBIENTAL DO ESTADO DE SÃO PAULO (CETESB). Decisão de Diretoria $n^{\circ}$ 045/2014/E/C/I, de 20 de fevereiro de 2014. Dispõe sobre a aprovação dos Valores Orientadores para Solos e Águas Subterrâneas no Estado de São Paulo - 2014, em substituição aos Valores Orientadores de 2005, e dá outras providências. Diário Oficial [do] Estado de São Paulo, Poder Executivo, São Paulo, v. 124, n. 36, 21 fev. 2014 . Seção 1, p. 53.

11. CEQG Chemicals. Canadian environmental quality guidelines.

Disponível em: http://st-ts.ccme.ca/en/index.html e http://www.ccme.ca/en/resources/canadian_environmental_quality_guidelines/. Acesso em: 05 jul. 2016.

12. BRASIL. Ministério do Meio Ambiente. Conselho Nacional do Meio Ambiente (CONAMA). Resolução no 344, de 25 de março de 2004. Disponível em:

http://www.mma.gov.br/port/conama/legiabre.cfm?codlegi=445. Acesso em: 02 dez 2017.

13. BRASIL. Conselho Nacional do Meio Ambiente (CONAMA). Resolução no 344, de 25 de março de 2004. Disponível em:

www.ibama.gov.br/licenciamento/modulos/arquivo.php?cod_arqweb=con344-04. Acesso em: 07 nov. 2016.

14. ROCHA, AF. Cádmio, chumbo, mercúrio: a problemática destes metais pesados na saúde pública? 2008/2009. Faculdade de ciências da nutrição e alimentação. Universidade do Porto. Disponível em:

https://repositorioaberto.up.pt/bitstream/10216/54676/4/127311_0925TCD25.pdf. Acesso em: 04 maio 2016. 
15. GUIMARÃES GM. Avaliação da concentração de metais e elementos traço em amostras de sedimento do reservatório Guarapiranga, São Paulo-SP, Brasil. Universidade de São Paulo. Instituto de Pesquisas Energéticas e Nucleares. 2011. Disponível em: www.teses.usp.br/teses/disponiveis/85/85131/tde-26082011-101237/. Acesso em: 05 jul. 2016.

16. RUPPENTHAL, JE. Toxicologia. Santa Maria, RS. 2013. Colégio Técnico Industrial da Universidade Federal de Santa Maria. Disponível em:

http://estudio01.proj.ufsm.br/cadernos_seguranca/sexta_etapa/toxicologia.pdf. Acesso em: 13 out. 2016.

17. MENDES R. Patologia do trabalho. 2. ed. atual. e ampl. São Paulo: Atheneu, 2007. 